\title{
Había una vez... Historia de la Ingeniería
}

Esp. Cuevas, Alicia; Esp. Amarilla, Alicia; Ing. Meza, Rita; Mgter. Corvalán, Ruben (*)

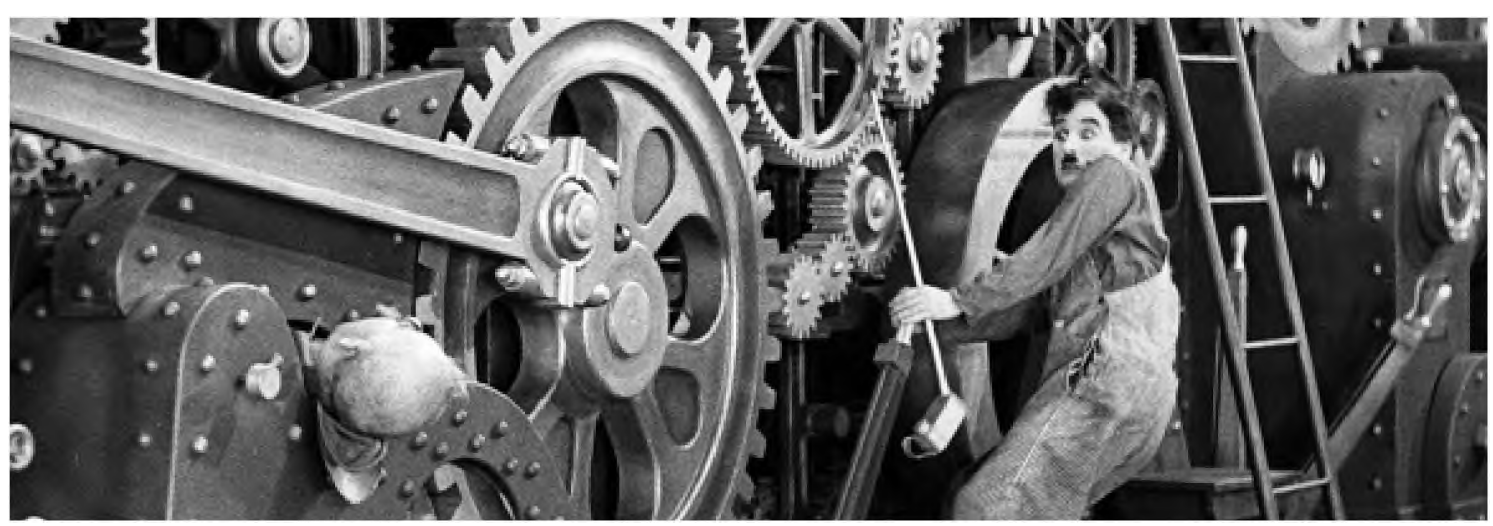

Resumen: este relato que inicia con la fórmula Había una Vez....pretende recorrer de manera amena, la Ingeniería, según las diferentes edades históricas, destacando los hechos y las personas, que con su ingenio e inventiva, fueron modelando la civilización, a lo largo de éstas épocas; a la vez de hacer un paralelismo entre las sociedades del mundo conocido y en particular sobre nuestro país Argentina. Para ello se ha realizado una revisión bibliográfica, recurriendo a libros de texto específicos, artículos de revistas especializadas y anales de centros profesionales. Empecemos a develar el camino de la Ingeniería a través de la Historia.

Palabras Claves: Ingenio, Construcciones, Inventos, Maravillas, Ingeniero.
Abstrac: This story that begins with the formula Once Upon a Time ... aims to walk in a pleasant way, Engineering, according to the different historical ages, bighlighting the facts and the people, who with their ingenuity and inventiveness, were modeling civilization, along these times; at the same time to make a parallelism between the societies of the known world and in particular about our country, Argentina. To this end, a bibliographical review has been carried out, using specific textbooks, articles from specialized journals and annals from professional centers. Let's start unveiling the path of Engineering through History.

Keywords: Ingenuity, Constructions, Inventions, Wonders, Engineer

(*) Grupo GRATOS: Grupo Regional de Administración, Tecnología, Organización y Sociedad. Departamento de Ingeniería. Facultad de Ciencias Exactas y Naturales y Agrimensura. Av. Libertad 5470. Corrientes. Mail: alisucuevas@ yahoo.com.ar 


\section{Ingeniería Primitiva:}

La Ingeniería, nace junto con el hombre y se remonta a 20.000 años antes de la era cristiana. Los hombres primitivos, se caracterizaron por investigar: el $\mathrm{Homo} \mathrm{Sa}$ piens (el hombre que sabe) y por construir: el Homo Faber (el hombre que hace) para satisfacer una necesidad. Para ello utilizó procedimientos rudimentarios, con una concepción ingenieril: inventando el hacha de silex (piedra pulida), y el punzón de hueso; ya sea para conseguir sus alimentos o como armas de defensa, contra los predadores; y descubre el fuego por el rozamiento del pedernal. En ésta etapa realizó construcciones elementales: Dolmens o megalitos (en bretón: mesa grande de piedra) un monumento funerario, consistente en varias losas clavadas en la tierra en posición vertical y una o más losas, apoyadas sobre ellas en posición horizontal; ejemplo de ello es el dolmen de Poulnabrone, condado de Clare, Irlanda, verdadero inicio de la construcción ingenieril. Pero el desarrollo de la ingeniería como tal, comenzó en el Asia Menor y África, hace unos 8000 años a. C., cuando los hombres dejaron de ser nómades, dando origen a los primeros asentamientos, con modestas edificaciones; donde los artesanos poseedores de una técnica fueron considerados los primitivos Ingenieros.

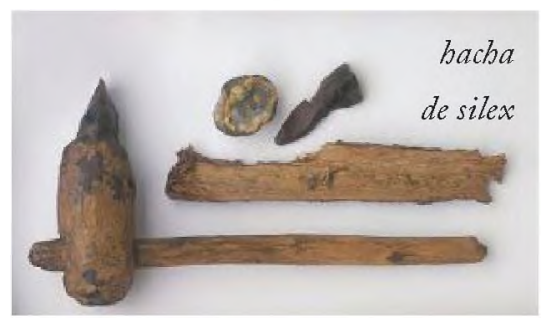

\section{Ingeniería Antigua: Era de las Estructuras}

Inicia hacia el año 4000 a.C. con los asentamientos alrededor de los ríos Nilo y Éufrates; cuando surge la escritura. El desafío era construir edificaciones estables. Este período finaliza con la caída del Imperio Romano de Occidente en el año 476 d. C.

Egipto: la vida civilizada junto al Nilo, se da entre el 3400 y el 1500 a.C. Crearon el papiro, como soporte de escritura, a partir de una planta acuática; y desarrollaron una escritura: el Jeroglífico con dibujos y símbolos. E1 Papiro Rhind o de Ahmes: es el $1^{\circ}$ manual de Matemáticas que se conoce, actualmente en el Museo Británico de Londres. E1 Maestro de Obras del Rey era un experto en construcciones, comparable a un Ingeniero Civil. Tenía conocimientos de Aritmética, Geometría y Física; y disponían como recurso de los esclavos, cuya utilización debían planificar.

E1 Maestro de Obras Imhotep: especialista en construir Pirámides, fue considerado el Padre de la Mampostería y el 10 Ingeniero Civil de la historia, por construir la Pirámide de Sakkara (pirámide escalonada o de peldaños) de base rectangular y $60 \mathrm{~m}$ de alto. En su tiempo alcanzó tanta reverencia por sus habilidades, que fue elevado a la categoría de dios egipcio después de su muerte. Las pirámides de Guiza, son monumentos emblemáticos de esta civilización, y en particular, las tres grandes pirámides o cenotafios (tumbas) de los faraones Keops, Kefrén y Micerino. 
Los Maestros de Obras Ineni y Senmut fueron expertos en la construcción de Obeliscos o Grandes Agujas del Faraón, (rayos petrificados de Atón, el disco solar). Estos bloques de granito, que procedían de las canteras de Asuán, eran colocados a la entrada de los templos. En nuestro país, en Buenos Aires tenemos como monumento histórico el Obelisco, construido en 1936 con motivo del $4^{\circ}$ Centenario de la Fundación de la Ciudad por Pedro de Mendoza. Tiene $68 \mathrm{~m}$ de alto y fue obra del Ingeniero Alberto Prebisch.

Mesopotamia: en la llanura de los ríos Tigris y Éufrates, se estableció el reino de Babilonia entre el 1100 y 561 a. C. E1 Rey Hammurabi surge como Director de Obras, y su legado el Código de Hammurabi: es el conjunto de leyes más antiguo, entre ellas la responsabilidad profesional de los ingenieros respecto de sus construcciones. Este bloque de basalto escrito, era considerado de origen divino, ya que fue entregado por el dios Shamash. Actualmente se halla en el Museo del Louvre

Bajo el dominio del Rey Nabucodonosor II, surgieron los jardines colgantes como regalo a su esposa Amytis, hija del rey de los medos; para demostrar su amor por ella y para que le recordaran las hermosas montañas de su florida tierra, tan diferentes de las grandes llanuras de la mítica ciudad de Babilonia.

Grecia: el centro del conocimiento se desplazó a las ciudades de Micenas, Atenas y Esparta, entre los años 1400 y 100 a.C.
Los griegos usaron la geometría y descubrieron que la naturaleza tiene Leyes Generales, que podían describir.

E1 historiador Herodoto introduce el título de Architekton. Pero el $1^{\circ}$ Ingeniero del mundo griego fue Pytheos, constructor del Mausoleo de Halicarnaso, quien combinó: el pedestal elevado, el templo griego y el túmulo egipcio. Este monumento funerario fue construido para Mausolo: sátrapa (gobernador) del Imperio Persa; en Halicarnaso (actual Turquía). Además Pytheos fue el $1^{\circ}$ que entrenó a sus aprendices en escuelas y escribió tratados para los constructores.

Los griegos eran grandes navegantes y por ello Dinócrates realizó los planos y Sostratus construyó el Faro, (el 1º del mundo). La torre de $110 \mathrm{~m}$ de altura fue construida en la isla de Pharo (Alejandría) como punto de referencia del puerto.

También Arquímedes, aparte de sus estudios sobre geometría y mecánica; inventó un tornillo sin fin para extraer agua. Consiste en un enorme tirabuzón, que gira accionado por una manivela en su parte superior, permitiendo elevar el fluido situado por debajo. (Tornillo de Arquímedes)

Herón creó la Eolípila: consiste en una esfera metálica de la cual salen 2 tubos curvos. Al calentar el agua de la esfera, el escape de vapor por los tubos hace que el mecanismo comience a girar, siendo el precursor de la máquina de vapor.

Roma: su historia inicia en el año 500 a.C. con la República y luego continua con el Imperio hasta el S.V d.C. Los romanos fueron los grandes Ingenieros de 
1a antigüedad, ya que fueron incorporando las ideas de los países conquistados. En sus construcciones usaron la polea y el sifón invertido o bomba, en las tuberías de plomo. Las más de 200 ciudades romanas gozaban de sistemas de suministro de agua con calefacción, sistemas de drenaje, baños públicos y calles pavimentadas.

Estaban los Librators o niveladores, (los $1^{\circ}$ Agrimensores) y los Viarum Curator o Superintendentes de Caminos. Construyeron una red de carreteras o Vías, de $290.000 \mathrm{~km}$, que cubría desde Escocia hasta Persia. El $1^{\circ}$ Ingeniero Romano de la historia es Appius Claudius autor de la Via Appia de $200 \mathrm{~km}$ de longitud, pavimentada con bloques poligonales de piedra.

Los Aqualegus o Inspectores de Acueductos fueron expertos en esta construcción, para llevar suministro de agua a las ciudades, que recibían 150 litros de agua: por habitante y por día.

Los Ingenieros especializados en la construcción de puentes eran los Pontífices: que también tenían a su cuidado los puentes sobre el río Tíber. Crearon los puentes peatonales o Pedes Pontis. E1 término Pontífice se aplicó luego al jefe de la Iglesia Católica, como sinónimo de puente entre Dios y los hombres.

El Arcbitectus surgió como un especialista que dirigía a los artesanos. De la época del Imperio Romano es el Coliseo, anfiteatro construido en el siglo $I d$. $C$. y ubicado en el centro de la ciudad. Originalmente era denominado Amphitheatrum Flavium Romae, en honor a la dinastía
Flavia de emperadores que lo construyó, y pasó a llamarse Colosseum por una gran estatua: el Coloso de Nerón. Poseía capacidad para 50000 espectadores, y contaba con túneles subterráneos (hipogeo), que permitían a gladiadores y fieras aparecer en la arena en distintos puntos; también estaba preparado para ser inundado por un sistema de ductos de agua, y así librar batallas navales.

\section{Las 7 maravillas del mundo Antiguo, según Antipatro de Si- dón (poeta griego S II a.C.):}

La Gran Pirámide de Guiza: construida para el faraón Keops, es la más antigua que aún sigue en pie. Ya no brilla cuando refleja el Sol, por la desaparición su recubrimiento de caliza blanca pulida; además de haber perdido 15 metros de altura.

Los Jardines Colgantes de Babilonia: en actual Irak, fueron reducidos a ruinas, por los persas.

El Templo de Artemisa: en Éfeso (actual Turquía) fue destruido por un incendio. Alejandro Magno ordenó su reconstrucción, siendo destruido luego por vandalismo.

La Estatua de Zeus en Olimpia: ubicada en el interior del templo dedicado a la deidad, en la ciudad anfitriona de los juegos. Fue destruida por vandalismo.

El Mausoleo de Halicarnaso: en la actual Turquía, empezado por el sátrapa Mausolo y continuado por su mujer Artemisa, fue destruido por un terremoto. 
E1 Coloso de Rodas: forjado y ubicado en el puerto de la ciudad de Rodas en la isla homónima de Grecia. Fue des- truido por causa de un terremoto.

El Faro de Alejandría: en Egipto, también fue destruido por un terremoto.

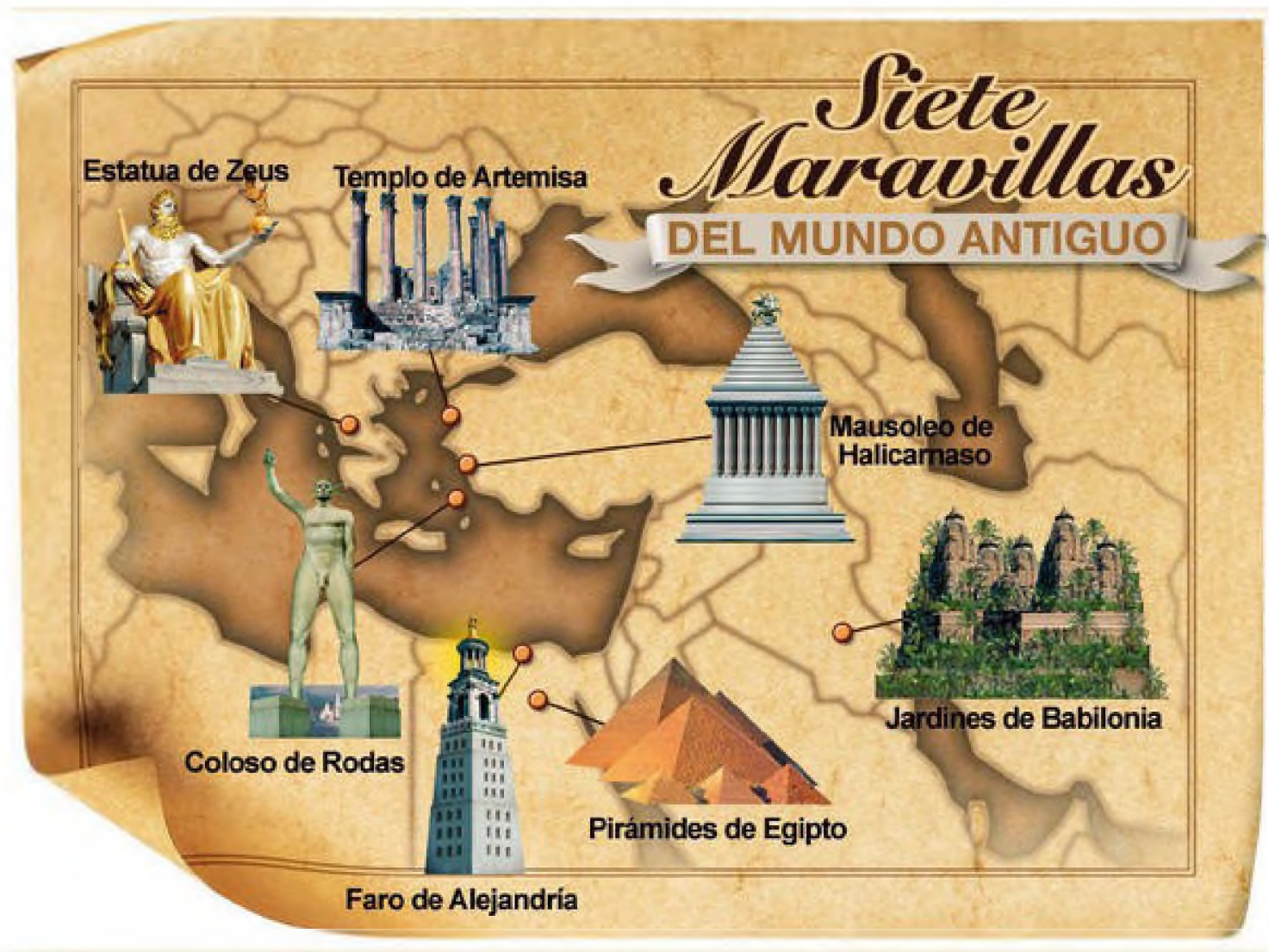

\section{Ingeniería Medieval: Era Feudal y Renacimiento}

Inicia luego de la caída del Imperio Romano de Occidente, en el año 476. Su desafío fue la construcción basada en la fuerza no humana o fuentes de Potencia. Este período se extiende hasta el 1492 con el descubrimiento de América.

Europa: se construyeron fortalezas rodeadas de altas murallas, con paredes de hasta $6 \mathrm{~m}$ de espesor (Castillo de Manzanares, España); algunas tenían fosos y se accedía por puentes levadizos En este período se utilizó por primera vez la palabra Ingeniero, del latín Ingenium e ingenerare: crear. Ello se debe a la construcción de un INGENIO: máquina semejante a una catapulta usada para el ataque de feudos; siendo el operador de esta máquina de guerra, el INGENIATOR. Las principales fuentes de potencia fueron: la fuerza hidráulica: los molinos de agua; la fuerza eólica: los molinos de vientos, y el caballo: junto con las ruedas, aparecen las carretas y los carruajes. Otros avances fueron: el timón girato- 
rio y las velas para los barcos; nacieron así las carabelas, provistas de sólidos cascos que las hacían más veloces. Utilizaban los portulanos o mapas, de los puertos conocidos.

E1 alemán Johannes Gutenberg ideó la imprenta mecánica con tipografía móvil. Los manuscritos eran realizados por de 9 a $12 \mathrm{~m}$ de ancho y alturas de $45 \mathrm{~m}$ o más; gracias a la invención del arco gótico y los arbotantes, o arcos de apoyo externo, que permitieron hacer estructuras más livianas.

A fines de la Edad Media, aparecen los Ingenieros - Arquitectos del Renacimiento:

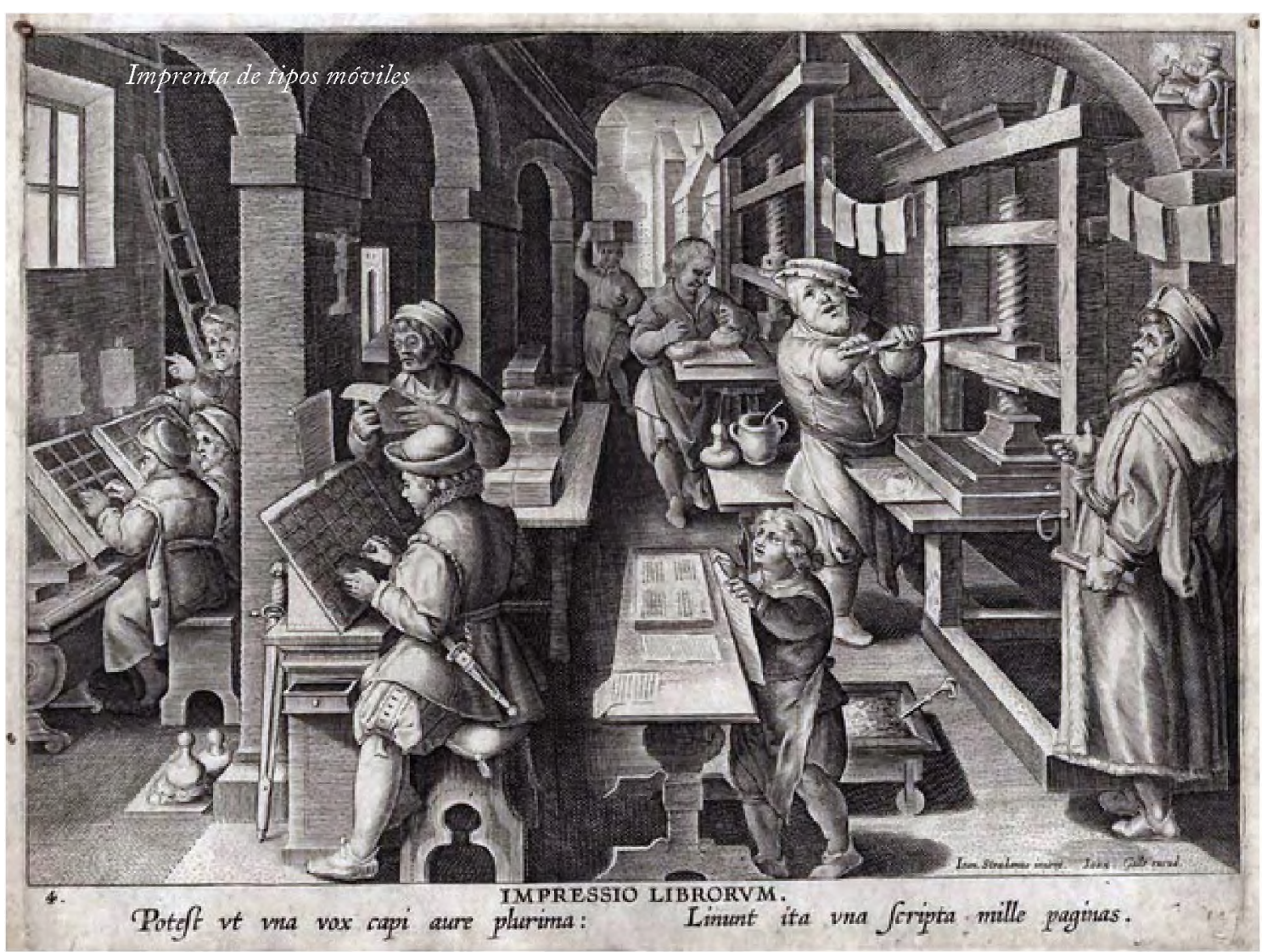

los monjes y frailes, a encargo del clero y los nobles. La Biblia fue el primer libro utilizado para demostrar el potencial del invento, al llevar el conocimiento a una población más amplia

E1 cristianismo desarrolló nuevas técnicas de construcción en las Catedrales góticas como la de Nôtre Dame, con naves
- Galileo Galilei: descubrió la ley fundamental de la caída de los cuerpos y estudió el comportamiento del movimiento del péndulo. Inventó el termómetro de agua ó termoscopio, que contenía agua con unas gotas de alcohol, siendo la primera forma de medir la variación de la temperatura. Construyó el Telescopio, 
con una lente convexa delante y una lente ocular cóncava. Con él observaba la Luna, las estrellas y descubrió las fases de Venus; indicando que el planeta giraba alrededor del Sol; su contribución fue el Método Científico.

- Leonardo de Vinci: entre sus obras se cuentan: el gato similar al que se usa en el automóvil, el Odómetro, la Rueda dentada, el Juego de poleas, el troquel para acuñar monedas en los Estados Pontificios, la Excavadora que avanza sobre rollos de madera, el hidrómetro, el traje de buzo, el $1^{\circ}$ paracaídas y sus máquinas voladoras: el ornitóptero y el tornillo aéreo, precursor del Helicóptero.

\section{ORIENTE}

- China: desarrollaron la química y la óptica: perfeccionando las gafas, con lentes de aumento sobre molduras. Otro avance fue el papel fabricado a partir de residuos de seda, paja de arroz, y cáñamo; Descubrieron la pólvora, primer explosivo conocido, que utilizaron en la fabricación de fuegos artificiales y con usos bélicos, en cañones.

Para determinar direcciones en el mar abierto, colocaban una aguja imantada en una vasija llena de agua, dando origen a la Brújula. Luego se le añadió una rosa de los vientos, con los puntos cardinales.

Según la tradición china, la historia de la seda fue un secreto durante tres milenios. El arte de fabricar seda era propio de la corte, donde se enseñaba a criar los gusanos de seda, dando lugar a la sericicultura.

Una de sus más grandes realizaciones fue la Gran Muralla China: cuya distancia de un extremo a otro del muro es de aproximadamente $2240 \mathrm{Km}$; sin embargo, hay más de $4080 \mathrm{Km}$ de muro en total. Casi toda la muralla tiene aproximadamente 10 $\mathrm{m}$ de altura, $8 \mathrm{~m}$ de espesor en la base, y se reduce hasta $5 \mathrm{~m}$ en la parte superior, donde corre un camino pavimentado. La muralla tiene 25000 torres en su parte principal y otras 15000 torres separadas de ella. Es la única construcción que puede verse desde el espacio exterior.

- Arabia: para moler el trigo desarrollaron molinos de viento, que tenían de seis a doce velas cubiertas con hojas de palma o tela; que se movían por el viento constante del desierto, a modo de puertas giratorias. Realizaban la refinación del azúcar, y crearon saladeros para la conservación de las carnes. Se destacaron en la fabricación de jabones y destilación de perfumes; al combinar aceites vegetales y compuestos aromáticos, tales como el aceite de tomillo y esencias florales.

Una de las obras más importantes del arte hispanomusulmán, fue la Mezquita Mayor de la Ciudad de Córdoba, (España) por su tamaño y suntuosidad. Cuenta con un bosque de columnas que rematan con arcos de herradura: hechos de piedra y ladrillo y con arcos trilobulados.

Introdujeron la numeración arábiga con su innovación el 0 : cero, y también desarrollaron el juego de Ajedrez. Cuenta la leyenda que para evitar el avance del Rey Alfonso VI en Andalucía, el Rey A1Mutamid mandó una embajada dirigida por Abenamar, su consejero; que encon- 
tró al Rey Alfonso y lo invitó a su tienda a hablar. Durante la conversación Abenamar descubrió que el monarca era un gran aficionado al ajedrez. La partida no sería solo un entretenimiento, por cada jugada se apostarían granos de trigo: dos granos por la primera casilla del tablero, cuatro por la segunda, 16 por la tercera, etc. Al finalizar la partida Alfonso comprobó que en toda Castilla no había trigo suficiente para pagar la derrota.

Así Abenamar tuvo su mejor oportunidad para hacer un trato, y Alfonso debió retirar sus tropas de las tierras de Al-Mutamid. Realidad o ficción una partida de Ajedrez evitó la guerra.

\section{Argentina antes de 1492}

En nuestro territorio, tuvieron lugar diferentes civilizaciones, con diverso grado de desarrollo ingenieril.

Incas: a la llegada de los conquistadores europeos, el Imperio Inca ocupaba el N.O. del actual territorio argentino. Sus ingenieros dominaban el uso de la piedra que unían sin argamasa. Fueron hábiles constructores de templos y fortificaciones. Crearon largos caminos en línea recta, de canto rodado, de $1 \mathrm{~m}$ de ancho; con muros de contención a los lados, cercas de flores y arboledas. Para acortar distancias el trazado recorría las cumbres de los cerros y los fondos de las quebradas; eran para ser recorridos a pie, ya que no conocían la rueda. A lo largo del camino cada 7 leguas, se levantaron tambos o postas: complejos habitacionales cuadrangulares para descansar, con paredes de piedra de
1,50 m de espesor (Angualasto en la Rioja). En el camino se encontraban montículos de piedras sueltas o apachetas, que eran apiladas por los transeúntes. Fueron Ingenieros hidráulicos: trazaron canales de riego para aprovechar el agua del deshielo. Dominaban el uso del bronce. Levantaron fortalezas o Pucarás: como en Tilcara (Jujuy). Construyeron atalayas de observación o morros, para su defensa: Famatína en la Rioja. Sus viviendas eran circulares de piedra, con hasta 8 habitaciones alrededor de un amplio patio, su techo era de cuero o fibras tejidas y el piso era de barro batido (ruinas de Santa Rosa en Tastíl, Salta).

Tobas y Matacos: vivían en chozas precarias en la zona del Chaco

Charrúas y Querandíes: eran nómades, en busca de caza y pesca; tenían tolderías de cueros de animales y soportes de ramas, que trasladaban.

Guaraníes: ocuparon el N.E; sus viviendas colectivas eran cilíndricas: de troncos, barro y paja.

\section{Ingeniería Moderna: Era de la Mecánica}

Inicia en 1492 con el descubrimiento de América, y se extiende hasta 1789 con la revolución francesa. Aquí tiene lugar el encuentro de los Mundos: el Viejo Mundo: Eurasia y África, con el Nuevo Mundo: América, y posteriormente el Novísimo Mundo: Australia (1770). El desafío es crear dispositivos para el trabajo repetitivo y convertir la energía en movimiento. 


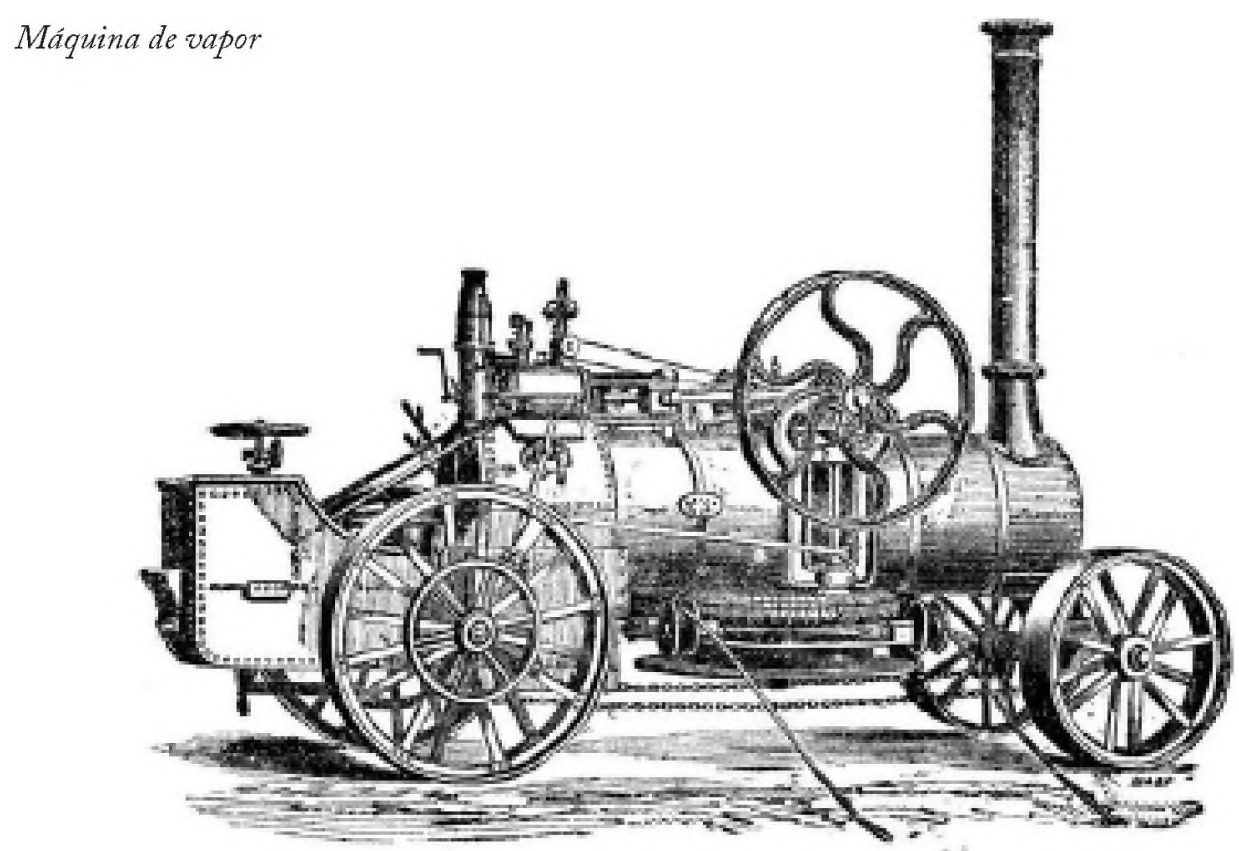

- Holanda: Daniel Gabriel Fahrenheit inventa el termómetro de mercurio (que hoy utilizamos) y añade una escala en el cristal, para una medición más fácil y fiable. El grado Fahrenheit $\left({ }^{\circ} \mathrm{F}\right)$ es una escala que establece como $\mathrm{T}^{\circ}$ de congelación del agua: $32^{\circ} \mathrm{F}$ y To de ebullición del agua $212^{\circ} \mathrm{F}$.

- Francia: Sebastien Le Preste Vauban: es considerado el $1^{\circ}$ Ingeniero de Francia, la obra de su vida fue el Puerto de DunKerque, en el canal de La Mancha; construido como una fortaleza en la arena. Desarrolló la Ingeniería Militar y fue el creador del Corps du Génie, el Cuerpo de Ingeniería Militar.

- Escocia: de la Eolípila de Heron, Thomas Newcomen la adapta e inventa la Bomba Atmosférica para sacar el agua que invadía las minas de carbón. James Watt a partir de ella crea una máquina que movía más agua y consumía menos combustible: la Máquina de Vapor, que transforma la energía térmica de una cantidad de agua, en energía mecánica.

- Inglaterra: la $1^{\circ}$ Revolución Industrial tuvo lugar con la Máquina de Vapor, que permitió mover máquinas: coches, locomotoras y barcos; y en la industria textil, su uso favoreció la exportación. Un pequeño grupo de ingenieros, formó la Sociedad de Ingenieros; John Smeaton director del grupo, fue el primero en darse el título de Ingeniero "Civil" para señalar que su incumbencia no era militar. Esta sociedad constituyó la Institution of Civil Engineering en 1828, iniciando una especialización. A Smeaton se debe la invención del primer cemento hidráulico de uso en la construcción.

- América: en Filadelfia Benjamín Franklin inventó el pararrayos. Este ins- 


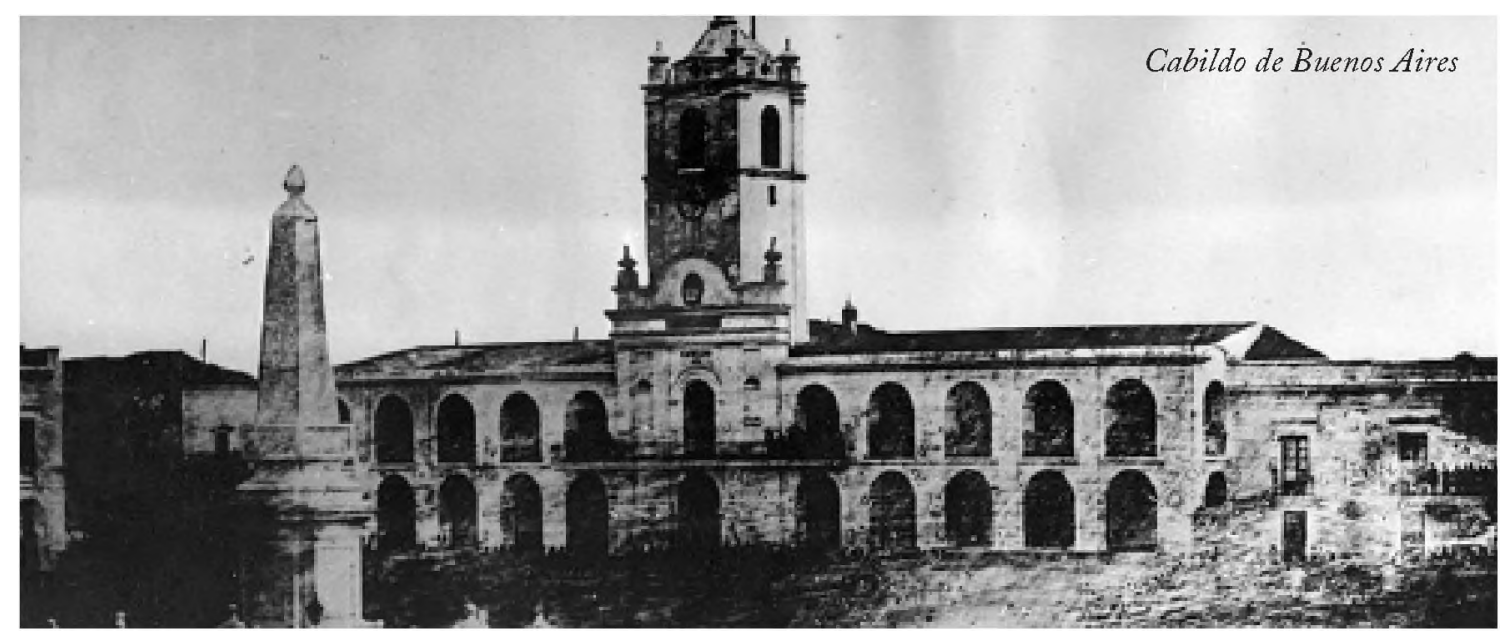

trumento atraía el rayo ionizado del aire para conducir la descarga hacia la tierra, y así no cause daños a las personas o construcciones. Las puntas captadoras o puntas Franklin, pueden ser únicas o múltiples.

\section{Argentina en el Siglo XV al 1789:}

El Virreinato del Río de la Plata fue creado el 27 de julio de 1776 por Carlos III. Lo integraban siete provincias: Buenos $\mathrm{Ai}^{-}$ res, Tucumán y Cuyo (actual territorio argentino), Potosí, Charcas y Santa Cruz de 1a Sierra (actual Bolivia) y Paraguay.

Bs As Colonial: las casas eran rectangulares de adobón o adobe gigante, con paredes de $1 \mathrm{~m}$ de espesor con techos de paja, ventanas pequeñas y pisos de tierra apisonada. Estaban rodeados por un cuadrado de tapias o empalizada, a manera de fuerte, rodeado de un foso de $12 \mathrm{~m}$ de ancho. En España el Ingeniero Cristóbal de Rodas proyecta un mejor fuerte; pero es el toscano Bathic de Filicaya quien se radica en Bs As y realiza su construcción. Luego el español José Bermúdez de Castro, $1^{\circ}$ Ingeniero militar graduado completa dichas obras. Las Leyes de Indias disponían que en las ciudades se fundara un Cabildo, que en sus inicios funcionó en casas particulares, hasta la edificación del recinto propio, a lo largo de 30 años (1718- 1748). El edificio actual esta recortado en su estructura. La Catedral de Buenos Aires se originó como una pequeña Iglesia; y en 1724 se inició la construcción del nuevo templo, que demandó 56 años, hasta su finalización en 1780. E1 Puerto era un muelle de madera, y servía de puerta de entrada y salida de los productos de los saladeros: $1^{\circ}$ industria de exportación de charqui y cecina. Luego se inicia la fabricación de velas de sebo para el alumbrado público porteño y se instalan hornos de ladrillo para las tejas musleras. El medio de transporte era la carreta tirada por bueyes; se juntaba la tropa de carretas, que recorrían 7 leguas por día. En el camino existían postas para 
dar alojamiento, mudar animales y dar de comer a los viajeros. Transportaban plumas, pieles y aguardiente.

Surgen los Alarifes o Maestros de Obras, (en árabe: alarif= maestro); el Ingeniero Martínez de Zalazar: crea la Real Maestranza o escuela de aprendices. También estaba el Real Cuerpo de Ingenieros: que era parte del Ejército, integrado por ingenieros italianos, irlandeses, franceses, gallegos y flamencos. La Escuela de Náutica fue fundada por el Gral. Manuel Belgrano en 1799. Allí se enseñaba Aritmética, Algebra, Trigonometría, Cosmografía, Geometría Elemental y Práctica, Geografía e Hidrografía. En Córdoba, el Colegio de Monserrat, fue proyectado por José Luis de Tejada, que usó para su construcción piedra bola y se fabricaron tejas para sus techos. En 1808 la Universidad de Córdoba era la única del país y asume como Rector de la misma el Dean Gregorio Funes.

\section{Ingeniería Contemporánea}

Tiene lugar desde la Revolución Francesa en 1789, y se extiende hasta nuestros días.

Francia: en 1794 Napoleón Emperador de Francia funda la Ecole Polytechnique, $1^{\circ}$ Escuela de Ingeniería de ese país. Alexandre Gustave Eiffel dirigió la construcción de una torre totalmente de hierro de $300 \mathrm{~m}$ de altura, que se erigió en París para la Exposición Mundial de 1889.
Alemania: en respuesta a las epidemias surge la Ingeniería Sanitaria, $1^{\circ}$ sistema de saneamiento urbano.

EEUU: se inicia el transporte urbano con el tranvía en Nueva York en 1832, y luego aparece el subterráneo. El ferrocarril atraviesa el país con más de 110.000 $\mathrm{km}$ de vías férreas; nace la escuela de Ingeniería Ferroviaria. La Academia de West Point, fue la $1^{\circ}$ Escuela de Ingeniería y cuartel del Cuerpo de Ingenieros del Ejército. E1 Coronel Washington Augustus Roebling concretó el Puente de Brooklyn; diseño de su padre John Augustus Roebling; sobre el East River de Nueva York, a $40 \mathrm{~m}$ sobre el pelo del agua.

\section{Era de la Ingeniería Eléctrica:}

(1879) el desafío es usar la electricidad sin peligro para el hombre Con esta nueva fuente de energía, se produce la Segunda Revolución Industrial. En 1800 el científico italiano Alessandro Volta fabricó la primera pila eléctrica. Thomas Alva Edisson inventó el Fonógrafo, pero su máxima contribución al bienestar de la humanidad fue la bombilla eléctrica: una corriente eléctrica calienta y hace brillar un filamento de carbón o metal, el vacío del interior de la bombilla impide que el filamento se queme. Samuel Morse inventa el telégrafo eléctrico. El ingeniero eléctrico Nikola Tesla crea y patenta el sistema de corriente alterna. Nace el automóvil y en 1913 Henry Ford crea los modelos Ford T y Ford A; e incorpora la línea automática de montaje; reduce la jornada laboral a 8 hs, duplica el salario obrero, y fabrica 10 millones de unidades. 
Era de la Ingeniería Electrónica y de la Informática:

(1946) la electrónica supone el uso de componentes para controlar la electricidad. E1 desafío es procesar y mover conocimientos. Se da la Tercera Revolución Industrial.

Lee De Forest es considerado el " $\mathrm{Pa}$ dre de la electrónica" por que inventó el tríodo, válvula electrónica que amplifica todo tipo de señales: audio, radio y $\mathrm{TV}$. La electrificación produjo un verdadero cambio social, que inició en el alumbrado público, con lámparas de filamento. Michael Faraday crea el $1^{\circ}$ motor eléctrico, que convierte la energía eléctrica en energía mecánica; siendo utilizado tanto en los procesos industriales, como en los electrodomésticos. Jack Kilby inventa el $1^{\circ}$ circuito integrado o microchip, de uso en lo equipos electrónicos. Las megacomputadoras al estilo de ENIAC y Univac: de 30 toneladas de peso; dan paso a minicomputadoras. Se desarrolla Internet, originalmente ARPANET. Inicia la exploración espacial: desde el punto de vista científico y de explotación económica. La sonda Juno del programa espacial New Frontiers de la NASA; lanzada el 5 de agosto de 2011, desde el Centro Espacial Kennedy, (Florida); llegó a la órbita del planeta Júpiter el 5 de julio de 2016.

\section{Era de la Biotecnología y la Bioinge- niería:}

(1959) el físico Ernst Ruska y el Ingeniero eléctrico Max Knoll, desarrollan el Microscopio Electrónico: que usa electro- nes en lugar de fotones. El desafío: la transformación de los seres vivos en productos, con respeto al ser humano y la naturaleza. Inteligencia Artificial: es un programa de computación diseñado para auto-aprendizaje. Robótica: diseño y construcción de robots y aparatos que realizan trabajos, en sustitución de la mano de obra humana. Pueden ser de tipo: Industrial (brazo robótico para ensamblar autopartes) o Humanoide (e-Boy: niño robot en laboratorio de Suiza). El escritor de ciencia ficción Isaac Asimov, crea las tres leyes de la robótica:

1-Un robot no hará daño a un ser humano, o por inacción, permitirá que un ser humano sufra daño.

2-Un robot debe cumplir las órdenes de los seres humanos, a excepción que entre en conflicto con la 1oley.

3-Un robot debe proteger su propia existencia, en la medida que no entre en conflicto con las leyes previas.

Biomateriales: sustancias no farmacológicas en contacto con estructuras vivas, y dispositivos de uso clínico: implantes, materiales inertes, metales y cerámicos. Ingeniería Genética: se logra la decodificación del Código Genético, uso de organismos transgénicos y clonación. Bio-Medicina: Prótesis 3D. Cyborgs: sistema HombreMáquina: Marcapasos, Implante Coclear, Ojo Biónico.

\section{Era de la Socioingeniería:}

(1980) el desafío consiste en construir obras de acuerdo con la sociedad, la naturaleza y el medio ambiente. Uso de energías renovables. 


\section{Era de la Globalización:}

(2000) desafío: los Ingenieros deberán ser Interdisciplinarios o Multidisciplinarios, combinar en su formación conocimientos específicos del área; con otros temas: historia, política, economía, medicina, idiomas, etc.

\section{Argentina: Siglo XVIII - Actual}

10 Ingenieros Argentinos: Esteban de Luca: Ingeniero Militar oriundo de Bs As, fue Capitán de Artillería y Director de la fábrica de fusiles, utilizó el hierro de un meteorito, descubierto en el Chaco; para fabricar armas "hierro caído del cielo". Fray Luis Beltrán: oriundo de Mendoza, fue un Ingeniero autodidacta que se incorporó al Ejército de los Andes y se encargó de instalar la fundición para las armas.

La Máquina de Vapor: en 1846 se instala la $1^{\circ}$ máquina a vapor, en el Molino San Francisco de Buenos Aires y luego recorre sus calles la locomotora a vapor: la Porteña que se inauguró en 1857.

La Ingeniería: en 1856 se crea el Departamento de Ciencias Exactas en la Universidad de Bs As. Y el 16 de Junio de 1865 se crea la primera Carrera de Ingeniería en el país; en su homenaje ese día se celebra el Día del Ingeniero. Se debía aprobar un curso de 2 años de Matemáticas Elementales y 1 año de Física Experimental, y luego un programa de 18 materias. El título de ingeniero, también habilitaba como Agrimensor. Se contrataron profesores de $\mathrm{Eu}^{-}$ ropa: el Prof. Naturalista Pellegrino Strobel, el Matemático Dr Ing. Bernardino
Speluzzi y el Ing. Emilio Rosetti. En 1870, tiene lugar la $1^{\circ}$ promoción, compuesta por 12 Ingenieros: 1-Valentín Balbín- 19a (Bs As); 2- Santiago Brian, 21a (Entre Ríos); 3Adolfo Bütner, 21a (Bs As); 4- Jorge Coquet. 26a (Bs As); 5-Luis Augusto Huergo, 32a (Bs As); 6- Francisco Lavalle, 29a, (Montevideo); 7- Carlos Olivera, 27a, (Bs As); 8- Matías Sánchez, 25a (San Juan); 9Luis Silveyra, 21a, (Montevideo); 10- Zacarías Tapia, 20a (Bs As); 11- Guillermo Villanueva, 21a (San Juan); 12- Guillermo White, 26a (Bs As). El Ingeniero Luis Augusto Huergo, fue el $1^{\circ}$ de su promoción en graduarse y recibir su diploma el 6 de Junio de 1870, por lo cual en esa fecha en la Argentina, se recuerda el Día de la Ingeniería.

Salubridad: luego de la epidemia de Fiebre Amarilla (1871), se realiza la traza para suministrar agua del Río de la Plata, por medio de redes de cañerías maestras y distribuidoras de agua potable, para una población de 400 mil habitantes (180 litros por persona). Se eliminan las aguas servidas por un sistema de alcantarillado, conductos pluviales y cloacas.

Electricidad: en 1882 funciona la $1^{\circ}$ Central Eléctrica en Las Palmas, Chaco (Ingenio azucarero). Luego se instala otra en la ciudad de La Plata (1886), junto con el alumbrado público; y 1892 circula el $1^{\circ}$ tranvía eléctrico, que competía con el tranway o tranvía a caballo.

Centro Argentino de Ingenieros: se funda el 8 de marzo de 1895 con el nombre de Centro Nacional de Ingenieros, con 68 miembros fundadores.

Ferrocarriles: en el 1900, la red se ex- 


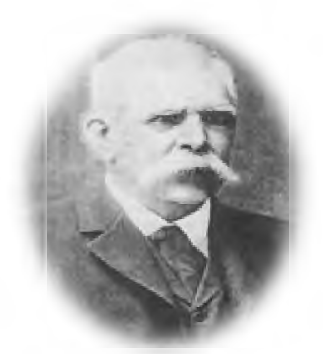

Ingeniero Luis Huergo

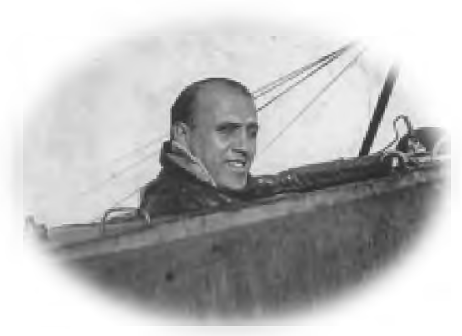

Ing. Electricista Jorge Newbery

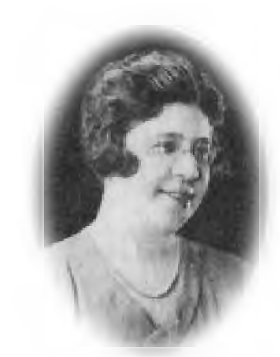

Ing. Civil Elisa Bachtent pande de $16000 \mathrm{~km}$ a $35000 \mathrm{~km}$, se construyen puentes, viaductos y estaciones. En 1910, tiene lugar la $1^{\circ}$ Exposición Ferroviaria Mundial en Buenos aires, en ocasión del Centenario de la Revolución de Mayo; participando: Alemania, Gran Bretaña, Estados Unidos, Italia, Bélgica, Francia y Suiza.

Puertos: en1911, el Puerto de Bs As se remodela con 4 dársenas paralelas dando lugar a Puerto Madero, según el Proyecto del Ingeniero Huergo, con una inversión de 27 millones de pesos oro. El puerto se empleaba para mover granos, carnes congeladas, cueros, maderas y carbón.

Jorge Newbery: fue el primer argentino en graduarse como Ingeniero Electricista en la Universidad de Cornell, en EEUU; siendo alumno de Thomas Alva Edison. A su regreso en 1913, junto a un grupo de veinticinco especialistas, fundó la Asociación Electrotécnica Argentina. En conmemoración de su natalicio, el 27 de mayo se celebra el Día del Ingeniero Electricista.

E1 $1^{\circ}$ Congreso Nacional de Ingeniería: en 1916, se realiza como homenaje de los Ingenieros Nacionales, al $1^{\circ}$ Centenario de la Jura de la Independencia Argentina.
En 1918: Elisa Beatriz Bachofen: egresa como Ingeniera Civil de la Universidad de Buenos Aires, siendo la $1^{\circ}$ Mujer Ingeniera de Argentina y de Latinoamérica. Dictó cursos para la capacitación técnica de la mujer en electricidad y mecánica, incentivándolas hacia la Ingeniería. Publicó la Guía del Inventor

De 1920 a 1950: aceleración de la Industria Nacional, se crea la carrera de Ingeniero Industrial.

Centro de Ingenieros de la Provincia de Corrientes: se crea el 13 de Noviembre de 1955, con 36 socios fundadores según consta en el 10 Acta; y en 1956: obtiene su Personería Jurídica. El CIC se ubica en Av. Pujol 1645, próximo al Parque Mitre; y tiene un Carácter Social y Gremial.

Consejo Profesional de la Ingeniería, la Arquitectura y Agrimensura de la Provincia de Corrientes: a instancias del CIC en 1957, se crea por Decreto Ley. E1 Consejo controla el Ejercicio Profesional y su Matriculación es Obligatoria. Su organigrama está dividido en 4 Departamentos: Urbanismo, Industria, Construcciones y Agrimensura. Se ubica en Rioja 1240. 


\section{Logros de la Ingeniería Argentina:}

Ingeniería Industrial: Torcuato $\mathrm{Di}$ Tella funda SIAM, donde se construyen los $1^{\circ}$ motores eléctricos (1933), y sus productos: heladera Siam 80, locomotora dieseleléctrica y auto Di Tella 1500.

Ingeniería Aeronáutica: se diseña $\mathrm{y}$ fabrica el IAe-27 Pulqui I, ("flecha" en Mapuche); $1^{\circ}$ avión a reacción de Sudamérica. Su longitud era de $9,7 \mathrm{~m}$, con una envergadura de $11,3 \mathrm{~m}$. Realiza su $1^{\circ}$ vuelo el 9 de agosto de 1947, alcanzando una velocidad máxima operativa de $720 \mathrm{~km} / \mathrm{hs}$.

Ingeniería Electrónica: se desarrolla CEFIBA, la $1^{\circ}$ computadora construida con 1405 transistores, con una capacidad de almacenamiento de 4096 palabras de 32 bits. (1962)

Ingeniería Civil: sobre las márgenes del río Paraná, entre las ciudades de $\mathrm{Co}^{-}$ rrientes y Resistencia, se inaugura el Puente Gral. Manuel Belgrano: el 10 de Mayo de 1973, luego de 5 años de obras; con una longitud total de $2800 \mathrm{~m}$.

Ingeniería Hidráulica: en 1998 se inaugura la Represa Binacional Yaciretá- Apipé, entre las ciudades de Ituzaingó (Corrientes - Argentina) y Ayolas (Misiones - Paraguay), cuyas obras iniciadas en 1983, culminaron en 2011, con una producción de $3100 \mathrm{Mw}$.

Ingeniería Nuclear: la Central Nuclear Atucha I, utiliza uranio levemente enriquecido; y cuenta con una potencia eléctrica bruta de 362 megavatios.

Ingeniería en Telecomunicaciones: se construyeron 2 satélites geoestacionarios de comunicaciones el ARSAT 1 y ARSAT 2. Cada uno de ellos tiene una envergadura de $16 \mathrm{~m}$ con los paneles solares.

\section{Las nuevas 7 Maravillas del Mundo Moderno}

Inspirado en las siete maravillas del mundo antiguo, el empresario suizo Bernard Weber fundador de New Open World Corporation realizó un concurso de votación internacional, para elegir las nuevas maravillas. Se admitieron estructuras creadas hasta el año 2000. Excepto las Pirámides de Guiza, (Maravilla del Mundo Antiguo, aún en pie) Los monumentos elegidos fueron dados a conocer el 07/07/07, en Lisboa (Portugal).

Petra: ubicada en el desierto de Jordania; la Ciudad Rosa, alberga tumbas y templos excavados en piedra.

Gran Muralla China: su extensión es de $4080 \mathrm{Km}$. de muros, y se la puede ver desde el espacio exterior.

Taj Mahal: mausoleo en la ciudad de Agra, construido por el emperador musulmán Shah Jahan para su esposa Muntaz Mahal.

E1 Coliseo: anfiteatro de la época del Imperio, ubicado en el centro de la ciudad de Roma.

Chichén Itzá: complejo de ruinas mayas en la península de Yucatán (México). Es una enorme pirámide con escalinata, llamada el Castillo, que dominaba la antigua ciudad.

Machu Picchu: antiguo poblado incaico construido entre las montañas Machu 


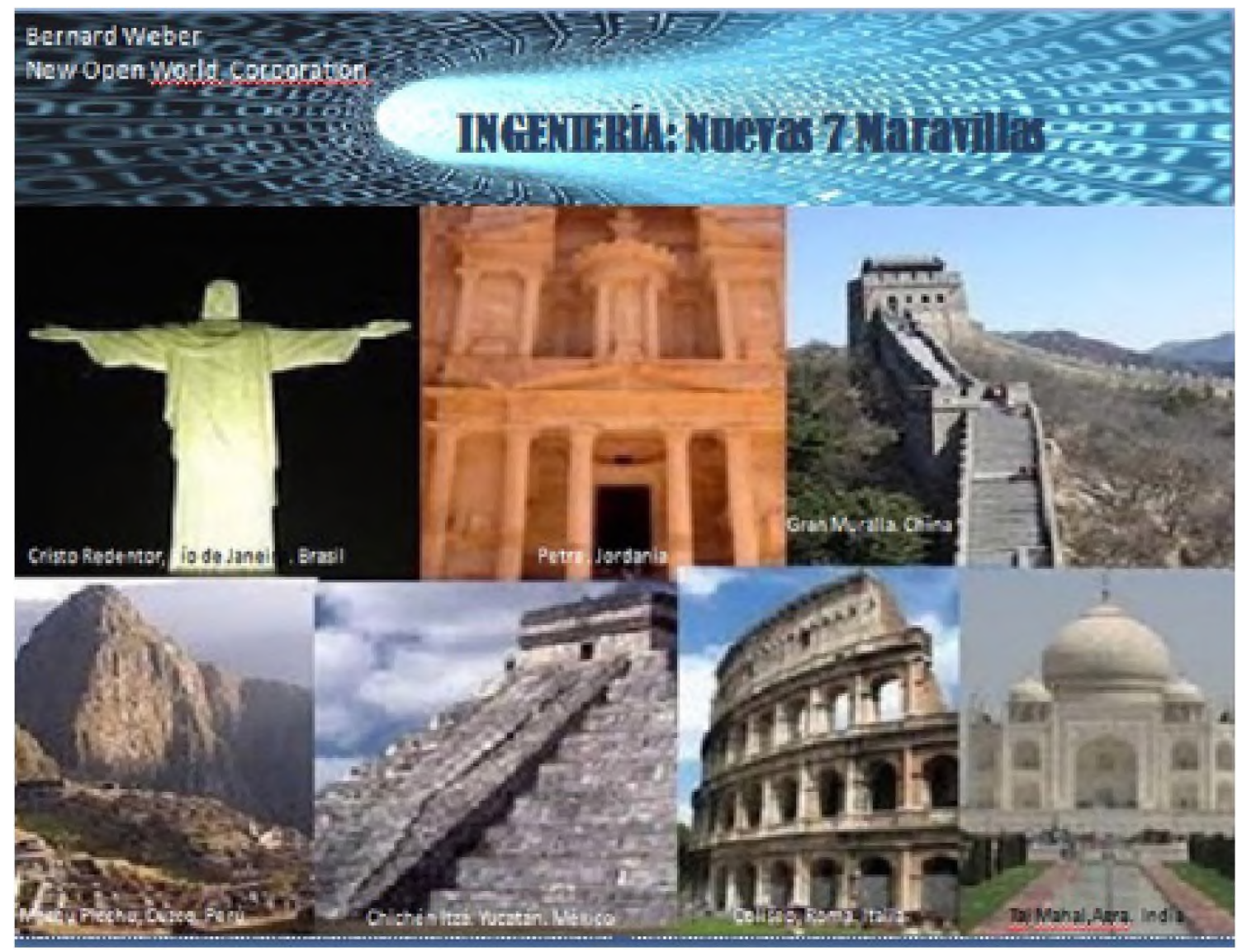

Picchu y Huayna Picchu; en la cordillera del Perú

El Cristo Redentor o Cristo de Corcovado: es una estatua de Jesús de Nazaret con los brazos abiertos hacia la ciudad de Río de Janeiro (Brasil). Mide 30,1 metros, con un pedestal de 8 metros; y está situada a $710 \mathrm{~m}$, en la cima del cerro Corcovado. Fue inaugurado el 12 de octubre de 1931.

\section{Las 7 Maravillas de la Ingeniería Argentina}

Fueron elegidas por el sitio SkyscraperCity, según likes; (junio/2008), que consagraron las siguientes obras:

Ciudad y Catedral de La Plata: la ciudad creada por Pedro Benoit, con diagonales y vastos espacios verdes; fue fundada el 19 de noviembre de 1882. La catedral de estilo gótico, es el templo más alto de toda América, y su construcción demoró 115 años.

Línea A del Subte de Bs As: fue la $1^{\circ}$ línea de subte de Ibero América, que comenzó a funcionar en 1913 por debajo de la avenida de Mayo. Su construcción demoró 2 años.

Represa Yaciretá - Apipé: la central hidroeléctrica se ubica en el río Paraná, sobre las Islas Talavera y Apipé, (Corrientes, Argentina) y la isla Yaciretá (Ayolas, Paraguay). Consta de 20 turbinas, con una 
potencia instalada de $4050 \mathrm{Mw}$ y una capacidad energética de $19.080 \mathrm{GW} / \mathrm{h}$.

Central Nuclear Atucha I: inicia su actividad en 1974 , siendo la $1^{\circ}$ de Latino América, entregando una potencia de 357 MWe con una tensión de 220 kilovolts. Luego se amplió con Atucha II.

Túnel Subfluvial Hernandarias: inaugurado el 13 de diciembre de 1969, cuenta con una longitud de $2937 \mathrm{~m}$; que se extiende $32 \mathrm{~m}$ por debajo de la superficie del río Paraná, entre Santa Fe y Entre Ríos.
Puente Libertador Gral. San Martín: puente internacional entre Puerto Unzué (Entre Ríos, Argentina) y Fray Bentos (Uruguay). Se inauguró en 1976; y con sus 5966 m, es el $3^{\circ}$ puente más largo de América.

Edificio Kavanagh: inaugurado en 1936, con $120 \mathrm{~m}$, fue el edificio más alto del mundo y el $1^{\circ}$ en contar con aire acondicionado. Su construcción escalonada dio lugar a terrazas jardín.

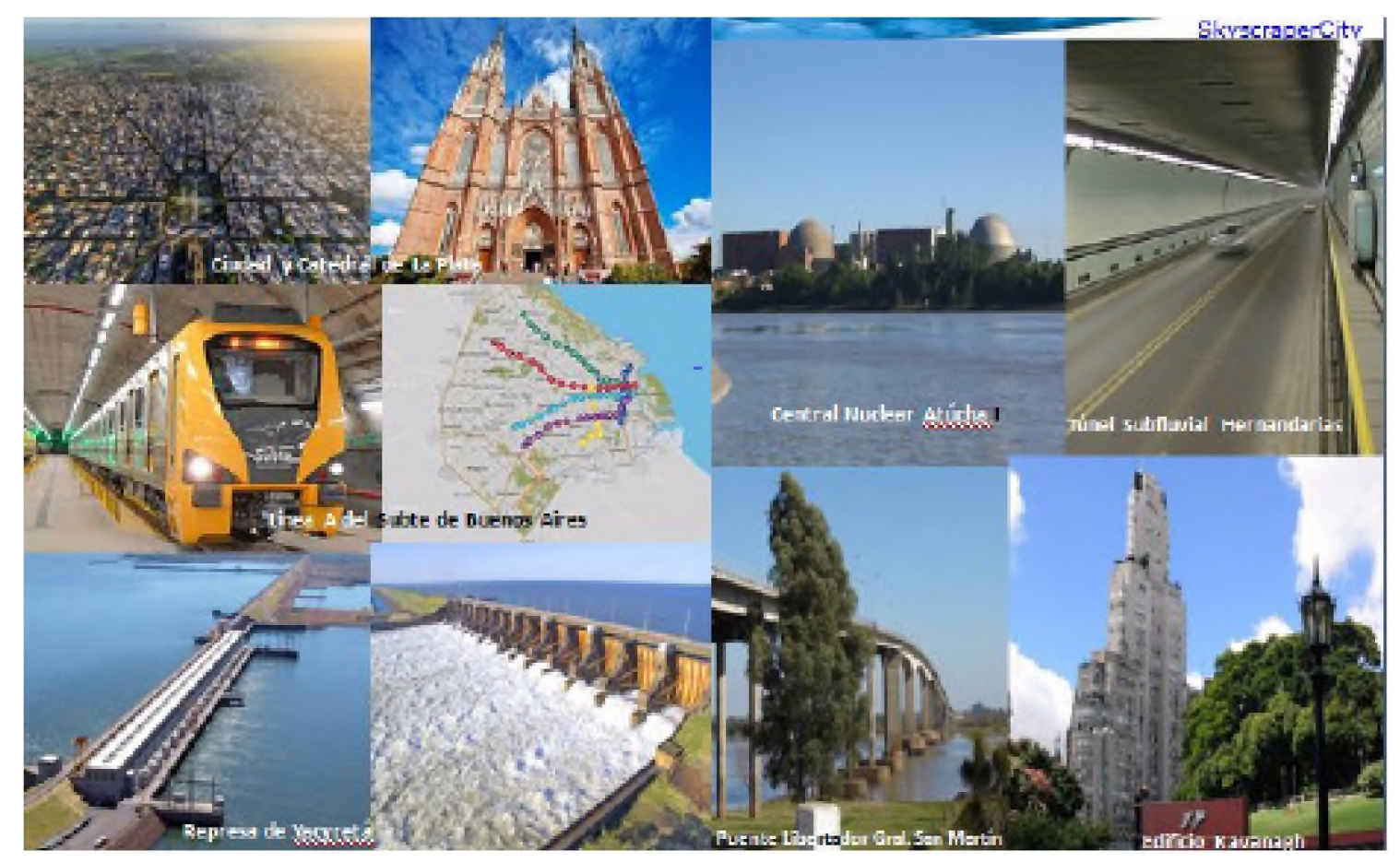

\section{Las 7 Maravillas Contempo- ráneas de la Ingeniería}

En abril de 2008, el sitio Web Art Urbanist; publicó una lista con obras de ingeniería colosales:

G-Cans Project, alcantarillas de Tokyo: en el subsuelo se levantan columnas de
20 metros de altura; diseñado y preparado para hacer frente a un tsunami. El sistema está propulsado por 14,000 turbinas, para bombear hasta 200 toneladas de agua por segundo.

Palm Island, en Dubai: son tres gigantescas islas artificiales, en la costa de los Emiratos Árabes Unidos. 
Barrera del Támesis, Londres: sistema de barreras de 520 metros de longitud, formado por 10 compuertas móviles $(3,700$ toneladas cda una).

Tower Bride, Londres: es un puente levadizo de $244 \mathrm{~m}$ de longitud, que cruza el Río Támesis. Cuenta con dos torres, cada una de $65 \mathrm{~m}$ de altura; y dos levas, que se desplazan hasta $83^{\circ}$, para el transito fluvial.

Aeropuerto internacional de Kansai, Japón: está localizado sobre una isla artificial ( $4 \mathrm{~km}$ de largo, por $1 \mathrm{~km}$ de ancho). El techo de la terminal parece el perfil de un ala de avión, y aloja el sistema de ventilación

Eurotúnel, Canal de la Mancha: el túnel une Calais/Coquelles (Francia) con Folkestone, Inglaterra. Fue inaugurado el 6 de mayo de 1994. Su longitud de $50 \mathrm{~km}$, lo hace el túnel submarino más largo del mundo.

Seagaia, playa artificial en Japón: situado en Kyushu Island; la playa posee un techo retráctil, produce olas para practicar surf y mantiene una temperatura de $28^{\circ}$.

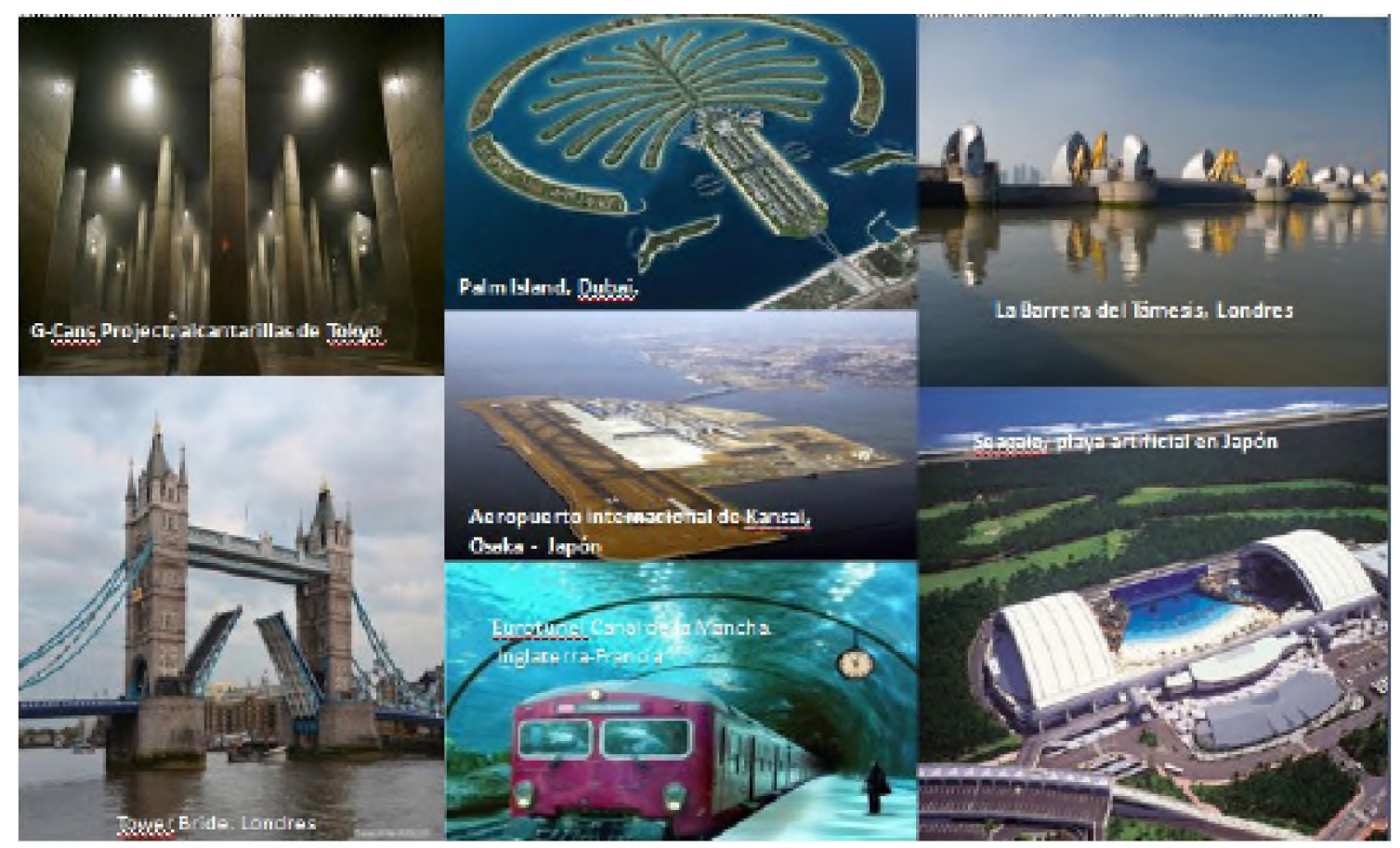

\section{Conclusiones:}

"El Ingeniero es un creador, crea lo que no existe" ( $†$ Ingeniero Eitel Hernani Lauría) "La Ingeniería estimula la creación de nuevos caminos"( † Ingeniero Roberto Pedro Echarte)

De la presente revisión, se desprende que la Ingeniería, por su misma naturaleza intrínseca, ha estado vigente desde los albores de la humanidad; creciendo a la par de las diferentes culturas y desarrollándose como una profesión, gracias a la inventiva de los ingenieros, que supieron dar respuesta a las necesidades concretas de su 
tiempo; lo cual permitió el progreso de la genio, nos acercará el mañana, que aún hasociedad. La historia seguirá escribiéndose, bita en la imaginación.

de la mano de hombres y mujeres cuyo in-

Bibliografía:

- Baca Urbina, G. et al. "Introducción a la Ingeniería Industrial” 2० Ed. Patria. 2014. México

- Sobrevila, M. A. "Ingeniería General". Editorial Alsina. 2001. Bs. As.

- Valencia Giraldo, A. "La Ingeniería, la Transhumanidad y la Posthumanidad" Revista Ingeniería y Sociedad. No 11- 2016. Medellín- Colombia
- Wright, P.H."Introducción a la Ingeniería" Ed. Iberoamericana S.A. Wilmington, USA. 1994

- Centro Argentino de Ingenieros "Historia de la Ingeniería Argentina" Bs As -1981

- Centro Argentino de Ingenieros "Historias de la Ingeniería Argentina” 2o Dossier. Bs As -2015

- Centro Argentino de Ingenieros "Historias de la Ingeniería Argentina” $3^{\circ}$ Dossier. Bs As -2015 